\title{
G1 Phase Process
}

National Cancer Institute

\section{Source}

National Cancer Institute. G1 Phase Process. NCI Thesaurus. Code C17355.

Phase of the cell cycle preceding DNA synthesis (Gap 1 phase). The subphases of G1 include competence, entry (G1a), progression (G1b), and assembly (G1c), based on the effects of limiting growth factors, nutrients, or inhibitors. 